\title{
Quantification of rasagiline mesylate by stability indicating RP-HPLC method: Development and validation
}

\author{
Rohith Ganapathi Bhatta, Sathesha Babu Birur Kotappa*, Sadashivaiah Rudragangaiah \\ Department of Pharmaceutics, Government College of Pharmacy, Rajiv Gandhi University of Health Sciences, Bengaluru 560027, India.
}

\begin{tabular}{l}
\hline ARTICLE INFO \\
\hline Received on: 28/03/2019 \\
Accepted on: 17/06/2019 \\
Available online: 01/09/2019 \\
\hline Key words: \\
Quantitation, rasagiline \\
mesylate, forced degradation, \\
liquid chromatography, \\
validated method.
\end{tabular}

\begin{abstract}
A novel reversed phase-high-performance liquid chromatography (HPLC) method for the estimation of rasagiline mesylate (RM), a potent anti-Parkinson drug in Active Pharmaceutical Ingredient (API), and tablet dosage form was developed and validated in the present research. HPLC instrument (Shimadzu) comprises ultraviolet detector and phenomenex $100 \mathrm{C} 18(250 \times 4.6 \mathrm{~mm}, 5 \mu \mathrm{m})$ column was utilized in the study. A mixture of acetonitrile and water in the ration of 50:50, adjusted to $\mathrm{pH} 3.0 \pm 0.05$ with ortho-phosphoric acid was used as the mobile phase. The chromatographic conditions; flow rate $0.8 \mathrm{ml} /$ minute, run time 6.0 minutes, injection volume $50 \mu \mathrm{l}$, and detection wavelength $268 \mathrm{~nm}$ were maintained during the study at room temperature. To ensure performance of novel method developed, it was validated according to International conference on harmonization guidelines. The developed method was subjected to the forced degradation studies to find out the stability indicating nature of the method by quantifying the RM in presence of its degradation products and the peaks which were responsible for the degraded products were not interfered with the API principle peak. The proposed stability indicating newly developed and validated method can be adopted for the quantification of RM in bulk and pharmaceutical formulations.
\end{abstract}

\section{INTRODUCTION}

Recently, the International Conference on Harmonization (ICH) has recommended any novel analytical method for the estimation of drugs as Active Pharmaceutical Ingredient (API) and in formulations, the developed method must be stability indicating in nature to access the effect of degraded products on estimation of principle API. The stability indicating nature of the developed method suggest that even in the presence of very minute quantity of degraded products, it enables to quantify the principle API. Hence, in the present research work, a novel analytical RP-HPLC method was developed, validated. The developed method is stability indicating in nature.

Rasagiline mesylate (RM) is a monoamine oxidase-B inhibitor (Fig. 1) used in the treatment of Parkinson's disease as a monotherapy or as an adjunctive therapy for advanced disease

\section{"Corresponding Author}

B. K. Satheesha Babu, Associate Professor, Department of Pharmaceutics, Bangalore 560027, India.E-mail: bksatishbabu@gmail.com conditions. For initial monotherapy, recommended dosage is $1 \mathrm{mg}$ once daily, whereas for adjunctive therapy with levodopa, $0.5 \mathrm{mg} /$ day initial dose is recommended. Literature review on analytical methods of RM reveals that there are very few methods, viz., reverse phase high-performance liquid chromatography (RP-HPLC) (Ravi et al., 2012; Sundaramurthy et al., 2011; Sunil Reddy et al., 2013), high performance thin layer chromatography (Singaram et al., 2012) and UV-visible spectrophotometry (Patel and Mulgund, 2013). All the reported methods in the literature either have longer retention time or tedious analytical procedures and stability indicating methods are seldom observed. Since RM is very potent drug with very lower dose as $0.5 \mathrm{mg}$ to $1 \mathrm{mg}$, a sensitive method was developed in the current study. A novel analytical method was developed to quantify RM in API and tablet formulation by RP-HPLC method. The developed method was validated as per the ICH guidelines which include System suitability, Specificity, Precision, Linearity, Accuracy, Ruggedness, Robustness, Limit of Detection (LOD), and Limit of Quantification (LOQ) (Chandran and Singh 2007; ICH 2003; 2005). In this work, we have adopted wherever necessary, the procedures by many published papers related to stability indicating 
HPLC method (Alarfaj, 2012; Blessy et al., 2014; Dey et al., 2017; Kongkiatpaiboon et al., 2017; Vamsi et al., 2016).

The primary objective of this research was to develop and validate an analytical RP-HPLC method comprises stability indicating nature by subjecting the RM to forced degradation, viz., acid hydrolysis, alkali hydrolysis, oxidation, photolytic, and thermal degradation to study the effect of degradation on estimation of RM.

\section{MATERIALS AND METHODS}

\section{Chemicals}

A RM reference standard and API were procured from Apotex Pvt Ltd, Bangalore, India and characterized by Fourier Transform Infra-Red and Ultra Violet spectroscopy. RM tablets (Rasalect-1) were purchased from local pharmacy. Analytical grades of Methanol, acetonitrile, and other HPLC solvents used in the analysis were purchased from E-Merck (India) Ltd. Mumbai, India. Ortho-phosphoric acid, hydrochloric acid, and sodium hydroxide were purchased from S D Fine Chem Ltd. Mumbai, India and were used for the study. Hydrogen peroxide was purchased from Karnataka Fine Chem, Bangalore, India. Millipore HPLC grade water used for the analysis.

\section{Instruments}

Electronic balance (Mettler Toledo), sonicator (Lab India), digital pH meter (systronics), hot air oven (Servewell), HPLC instrument (Shimadzu) consisting of ultraviolet detector equipped with LC solution software, Fourier-Transform InfraRed spectroscopy (Shimadzu IR-1S affinity), Ultra Violet Visible spectroscopy (Shimadzu-UV 1800).

\section{$\left(\mathrm{C}_{12} \mathrm{H}_{13} \mathrm{~N}\right) \cdot \mathrm{CH}_{4} \mathrm{SO}_{3}$}

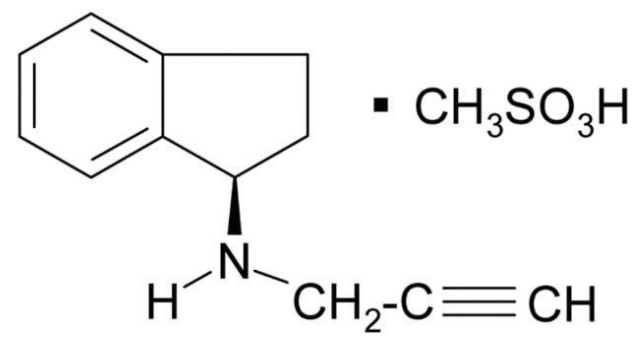

Figure 1. Chemical structure of RM.

Table 1. Chromatographic conditions for RM analysis.

\begin{tabular}{lc}
\hline Parameters & Conditions \\
\hline Stationary phase & $\begin{array}{c}\text { C18 }(250 \times 4.6 \mathrm{~mm}), 5 \mu \mathrm{m} \text { column } \\
\text { Mobile phase }\end{array}$ \\
to $3.0 \pm 0.05$ with ortho-phosphoric acid
\end{tabular}

\section{Chromatographic conditions}

The chromatographic separations were performed on a phenomenex $100 \mathrm{C} 18(250 \times 4.6 \mathrm{~mm}), 5 \mu \mathrm{m}$ column at room temperature using flow rate of $0.8 \mathrm{ml} /$ minute with run time 6.0 minutes and UV detection wavelength at $268 \mathrm{~nm}$. Injection volume was set as $50 \mu \mathrm{l}$. Acetonitrile and water in the ration of 50:50\% $\mathrm{v} / \mathrm{v}$, adjusted to $\mathrm{pH}$ to $3.0 \pm 0.05$ using ortho-phosphoric acid was used as mobile phase which was filtered $(0.2 \mu \mathrm{m}$ finer porosity nylon membrane filter) and degassed by sonication. Mobile phase is used as the diluent (Table 1).

\section{Preparation of standard stock solution}

RM standard equivalent to $100 \mathrm{mg}$ was dissolved in 100 $\mathrm{ml}$ of diluent to prepare standard stock solution. The stock solution was diluted to get a final standard concentration of $100 \mu \mathrm{g} / \mathrm{ml}$.

\section{Preparation of sample solution}

Twenty tablets each containing $1 \mathrm{mg}$ of rasagiline were weighed, average weight found, and finely powdered. The sample solution was prepared by taking weight equivalent to $10 \mathrm{mg} \mathrm{RM}$ from powdered 20 tablets into $100-\mathrm{ml}$ volumetric flask and kept for sonication with $75 \mathrm{ml}$ mobile phase for 30 minutes and shaken occasionally. After cooling to room temperature, the volume was made up with mobile phase, solution was filtered $(0.2-\mu \mathrm{m}$ nylon membrane filter).

\section{Validation}

The method developed was validated for the RM assay (1 mg per tablet strength) in formulation for different parameters as follows:

\section{System suitability}

Six replicates of prepared $100 \mu \mathrm{g} / \mathrm{ml}$ concentration of RM standard were injected. From standard preparation analysis by the developed method, the tailing factor obtained for RM peak should be less than 2 and theoretical plates of not less than 2,000 determines the column efficiency. Likewise six replicates of standard solution were injected, the mean value calculated for each determination and \% Relative Standard Deviation (RSD) should be less than $2 \%$.

\section{Specificity}

If developed method has the ability of measuring analyte response even in the presence of potential impurities, the method is said to be specific. Also, the absence of interferences of mobile phase and excipients with the principal analyte response peak denotes specificity. Sample and blank solutions were prepared and analyzed to check the interference of mobile phase with the analyte (RM).

\section{Precision}

Degree of scatter in terms of closeness of agreement among analyte responses from multiple sampling of the similar sample under prescribed conditions represents the precision. In the evaluation for precision, system precision, method precision, and intermediate precision were carried out. Six replicates (100 
$\mu \mathrm{g} / \mathrm{ml} \mathrm{RM}$ solution) of injections each for system and method precision was determined and examined. It was represented as $\%$ RSD of area counts of RM peak obtained. Ruggedness, which is also represented as intermediate precision, was carried out using different analysts, using different column, on different days, and on different instruments makes. RSD for overall set of data was calculated.

\section{Linearity}

Standard stock solution was serially diluted to get the different concentration ranged from 25 to $1,000 \mu \mathrm{g} / \mathrm{ml}$ of $\mathrm{RM}$ solution. At all the concentration levels, the peak responses were measured in triplicate. Linear regression analysis was carried out by plotting peak response versus concentration data. Linearity for $\mathrm{RM}$ response was determined by the correlation coefficient $\left(R^{2}\right)$ calculation, which shall not be less than 0.997 .

\section{Accuracy}

Accuracy was performed using marketed formulation. Known amount of samples were taken in a clean dried volumetric flasks separately. To these flasks were spiked by the addition of known amount of RM standards in three different levels, namely, 80\% (Level 1) 100\% (Level 2), and 120\% (Level 3) of sample concentration. The amount of RM recovered was calculated by subjecting these samples for analysis by the developed method.

\section{Robustness}

The capacity of an analytical method to remain unaffected by small but deliberate changes in method parameters measures robustness. It was investigated by varying detection wavelength and flow rate. For each variation system suitability (theoretical plates and tailing factor), parameters were checked. For each set of data, \%RSD of area counts was determined. Overall \%RSD between method precision data and each varied condition data represents the robustness. The developed method is said to be robust if conditions like system suitability should pass and overall $\%$ RSD not more than $2 \%$ were met.

\section{Limit of detection (LOD) and limit of quantification (LOQ)}

LOD represents the lowest possible detectable analyte amount in a sample, not necessarily be quantified. LOQ represents the lowest amount of analyte for which quantification is possible by developed method with suitable precision and accuracy. Serial dilutions were made and chromatographs were recorded till the drug solution gives response and peak area. The peak should be detected at the LOD level and the peak should be quantified at LOQ level by visual evaluation.

The percent relative standard deviation (\%RSD) for each validation parameter was obtained by adopting descriptive statistics using MS Excel.

\section{Forced degradation studies}

During stability studies investigated by subjecting RM to forced degradation studies. RM was exposed to different conditions of stress, such as acid hydrolysis, alkali hydrolysis, oxidation, and degradation by thermal and light. The aim was to study the ability of the developed method to measure the analyte response in presence of its degradation products.

\section{Stock Solution Preparation}

Accurately weighed and transferred $100 \mathrm{mg}$ of RM standard in to dry and clean $100 \mathrm{ml}$ volumetric flask, dissolved and diluted to $100 \mathrm{ml}$ with diluent, to get a concentration of $1,000 \mu \mathrm{g} /$ $\mathrm{ml}$. This solution was used as a stock solution for further studies.

\section{Acid and alkali hydrolysis}

Nearly, $10 \mathrm{ml}$ of RM stock solution was transferred to a $100-\mathrm{ml}$ volumetric flask. The solution was mixed with $10 \mathrm{ml}$ of $0.1 \mathrm{~N} \mathrm{HCl}$ or $0.1 \mathrm{~N} \mathrm{NaOH}$. The prepared solutions were kept at $80^{\circ} \mathrm{C}$ for 2 hours in a water bath. The samples were cooled at room temperature. The solution was neutralized with an amount of acid or base equivalent to that of the previously added. Then, volume was made up to $100 \mathrm{ml}$ with the diluent to get a final concentration of $100 \mu \mathrm{g} / \mathrm{ml}$.

\section{Oxidative degradation}

Nearly, $10 \mathrm{ml}$ of RM stock solution was transferred to a $100-\mathrm{ml}$ volumetric flask. The contents were then mixed with 10 $\mathrm{ml}$ of $3 \%$ hydrogen peroxide solution. The prepared solution was kept at $80^{\circ} \mathrm{C}$ for 2 hours in water bath and the reaction mixture was allowed to proceed at room temperature with intermittent shaking. Then, volume was made up to $100 \mathrm{ml}$ with the diluent to get a final concentration of $100 \mu \mathrm{g} / \mathrm{ml}$.

\section{Thermal degradation}

A standard drug of RM was exposed to a temperature of $80^{\circ} \mathrm{C}$ for 2 hours in hot air oven. Nearly, $100 \mathrm{mg}$ of dried powder is weighed and transferred to a $100-\mathrm{ml}$ volumetric flask, dissolved in diluent, and the volume is made up to the mark with the same, to get a concentration of $1,000 \mu \mathrm{g} / \mathrm{ml}, 1 \mathrm{ml}$ of above stock solution was diluted to $10 \mathrm{ml}$ with diluent to get a final concentration of $100 \mu \mathrm{g} / \mathrm{ml}$.

\section{Photolytic degradation}

Nearly, $10 \mathrm{ml}$ of stock solution $(1,000 \mu \mathrm{g} / \mathrm{ml})$ was exposed to UV light $(254 \mathrm{~nm})$ for 72 hours. Then, volume was made up to $100 \mathrm{ml}$ with the diluent to get a final concentration of $100 \mu \mathrm{g} / \mathrm{ml}$.

\section{Estimation of RM in marketed product (Rasalect 1)}

Standard Solution: Standard stock solution was prepared by dissolving RM standard equivalent to $25 \mathrm{mg}$ in $25 \mathrm{ml}$ of diluent. The above stock solution was diluted to get a final standard concentration of $100 \mu \mathrm{g} / \mathrm{ml}$.

Sample Solution: 20 tablets each containing $1 \mathrm{mg}$ of rasagiline were weighed, average weight found, and finely powdered. The sample solution was prepared by taking weight equivalent to $10 \mathrm{mg}$ rasagiline from powdered 20 tablets into 100$\mathrm{ml}$ volumetric flask and kept for sonication with $75 \mathrm{ml}$ mobile phase was added and sonicated for 30 minutes with intermittent shaking. Allowed to cool to room temperature and made up the 
volume. Then, the solution was filtered through $0.2-\mu \mathrm{m}$ nylon membrane filter.

Nearly, $50 \mu \mathrm{l}$ of standard and sample solutions were injected to the system and chromatographs were recorded. The calculations were performed on the comparative basis including the correction factor. The concentration was found by calculation using average peak areas of standard and sample as given in detail in Table 4.

\section{RESULTS AND DISCUSSION}

\section{RP-HPLC method development for RM}

Initially various parameters, such as mobile phase composition and mobile phase $\mathrm{pH}$, were varied and tried to finalize the chromatographic conditions. Percentage of acetonitrile and $\mathrm{pH}$ influenced the retention time and separation. Various mobile phases with different organic modifier and with different $\mathrm{pH}$ values in combination were tried. As acetonitrile was having the advantages of low background noise and strong elution effect, it was chosen over methanol for RM analysis to shorten analysis time and also there were no interferences from blank acetonitrile. Moreover, the addition of ortho-phosphoric acid in the mobile phase ( $\mathrm{pH} 3)$ contributed to better symmetry of chromatographic peaks, good symmetrical peak were obtained with mobile phase consisting of water and acetonitrile in the ratio $50: 50 \% \mathrm{v} / \mathrm{v}$ with Phenomenex $100 \mathrm{C} 185 \mu \mathrm{m}$ column within a short runtime of 6 minutes. The mobile phase selection depicts the less possibilities of variation compared to methods with buffers as found in literature, where weighing of ingredients are involved as a part of the mobile phase preparation procedure. Figure 2 illustrates the chromatogram with system suitability parameters obtained by the finalized mobile phase for $50 \mu \mathrm{l}$ injection of the RM assay preparation. The retention time for RM was only around 2.6 minutes which accounts for high turnout of the samples when compared to others with 4.152 minutes (Sundaramurthy et al., 2011), around 5.5 minutes (Ravi et al., 2013) and at 33.1 minutes (Sunil Reddy et al., 2013). There was no interference from blank at the retention time.
The method by Sundarmurthy et al. (2011) utilized a mobile phase which consisted of potassium dihydrogen phosphate buffer and conditions were $1.2 \mathrm{ml}$ flow rate and injection volume of $100 \mu 1$ to get retention time around 4.152 minutes, whereas in the proposed method, utilized only mixture of acetonitrile and water $\mathrm{pH}$ adjusted to 3.0 with o-phosphoric acid with $0.8 \mathrm{ml}$ flow rate, $50 \mu \mathrm{l}$ injection volume to achieve retention time of 2.6 minutes. In another method by Sunil Reddy et al. (2013), authors concentrated on estimation of process related impurities. The method could very well be utilized in bulk manufacturing industries and was a gradient elution technique based separation which was run for more than 70 minutes of runtime. RM retention time being around 31 minutes, it might be difficult to utilize the same in routine analysis of the quality control of samples where quick turnout of the sample is essential.

The objectives of the newly developed analytical method for RM was to achieve shorter retention time, less utilization of mobile phase, minimizing the errors during mobile phase preparation, and to make the method more economical by high turnout of the samples. The earlier researcher (Sunil Reddy et al) opted gradient elution technique of analysis since their prime objective was simultaneous estimation of process related impurities and degradation products, which resulted in increased retention time. Achieving low retention time in RM analysis by this method when compared to other methods in the literature, have the advantages of quick analysis and less consumption of mobile phase which make the developed and validated method to be cost effective.

\section{System suitability}

During the validation study, standard solution analysis was carried out by using validated method on different days. Theoretical plates and tailing factor for RM peak were calculated using LC solution system suitability software. Six replicate injections were analyzed and \%RSD was calculated. The tailing factor for the RM standard peak was found to be 0.981 , with

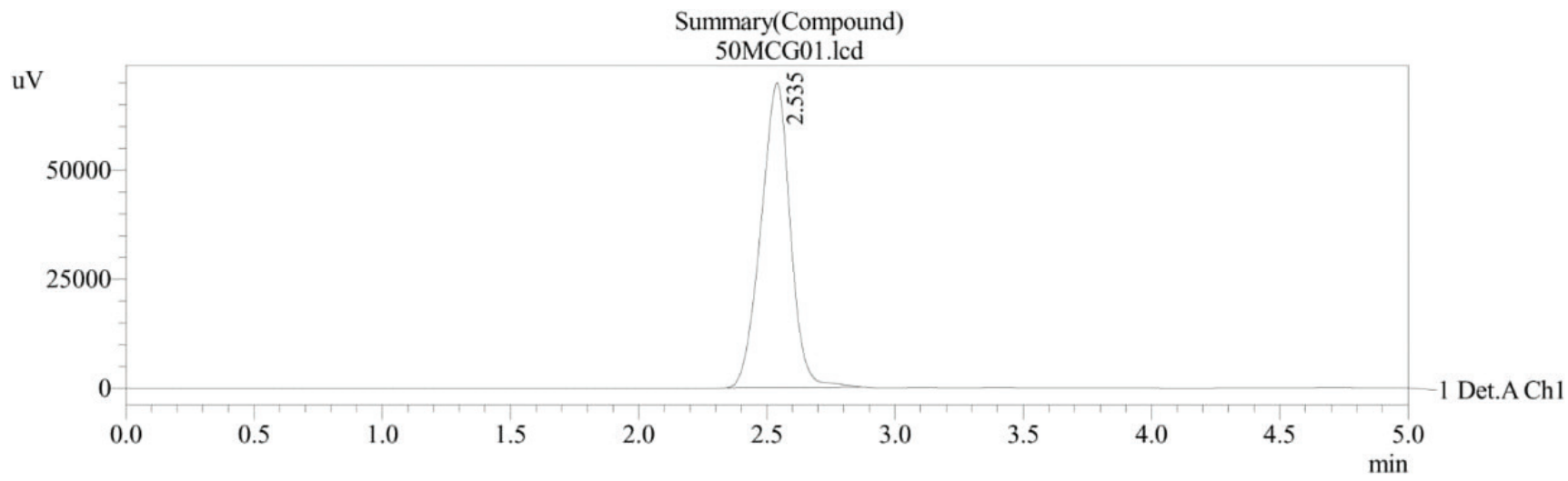

ID\#1 Compound Name: RASAGILINE MESYLATE

\begin{tabular}{|c|c|r|r|r|r|r|}
\hline Title & \multicolumn{1}{|c|}{ Sample Name } & Sample ID & Ret. Time & \multicolumn{1}{c|}{ Area } & Theoretical Plate\# Tailing Factor \\
\hline 50MCG01.lcd & RASAGILINE MESYLATE & SS & 2.535 & 557485 & 2111.528 & 0.983 \\
\hline
\end{tabular}

Figure 2. A typical HPLC chromatogram for RM. 
the theoretical plates 2,114.64 and the \%RSD for the mean area calculated for RM peak was $0.201 \%$. During the entire course of validation process, all the above system suitability parameters were met.

\section{Specificity}

There were no interferences from co-eluting peaks from blank indicates that the RM peak is homogeneous.

\section{Precision}

The individual and overall \%RSD (not more than 2\%) was achieved successfully in all the precision parameters. \%RSD of the area counts for six injections of the standard solution was 0.19 for the system precision. That for the method for RM in the sample was 0.16 which indicates and proved the method precision. The individual \%RSD of amount present for RM in intermediate precision was found to be within the limits and overall 0.23 with other instrument, analyst and column, and hence the method is found to be rugged (Table 2).

\section{Linearity}

The regression equation $y=10,061 x+58,291$ obtained by plotting peak response versus concentrations plot, with a correlation coefficient $\left(R^{2}\right)$ was 0.9999 indicating that the response is linear over the range of $25-1,000 \mu \mathrm{g} / \mathrm{ml}$ (Fig. 3).

\section{Accuracy}

Sample prepared at each three levels of the accuracy studies showed the recoveries ranged from $100.76 \%$ to $101.82 \%$. The percentage recovery was found within the acceptable limits $(98 \%-102 \%)$. The individual and overall \%RSD of percentage recovery study was found to be well within $2 \%$, hence the method is accurate.

\section{Robustness}

The results obtained in all the deliberate varied chromatographic conditions (wavelength of detection and flow rate) were well within the limit. The validation data have been found within the limit which proves the robustness of the method (Table 2).

\section{LOD and LOQ}

In this method LOD was found to be $0.1 \mu \mathrm{g} / \mathrm{ml}$ (peak area 12,021) and LOQ was found to be $1 \mu \mathrm{g} / \mathrm{ml}$ (peak area 18,269).

\section{Forced degradation studies}

During forced degradation studies the RM was found to be degrading considerably in acidic, basic and oxidative stress condition. The RM solution during alkali stress $(0.1 \mathrm{M} \mathrm{NaOH}$ at $80^{\circ} \mathrm{C}$ for 2 hours) showed $88.49 \%$ degradation. During acid stress condition $\left(0.1 \mathrm{M} \mathrm{HCl}\right.$, heated at $80^{\circ} \mathrm{C}$ for 2 hours $)$ degradation showed $47.39 \%$ and oxidative degradation $\left(3 \% \mathrm{H}_{2} \mathrm{O}_{2}\right.$ at heated at $80^{\circ} \mathrm{C}$ for 2 hours) showed $31.32 \%$ degradation of RM. The degradation peaks in alkaline stress condition were observed at 3.09 and 3.85 minutes and that for acidic stress condition were observed at 2.85 and 3.81 minutes. The RM was found to be stable in thermal stress condition(at $80^{\circ} \mathrm{C}$ for 2 hours) and photo degradation (exposed to UV light for 72 hours), where it was observed negligible degradation of $0.903 \%$ and $0.828 \%$, respectively (Table 3 ). However, chromatogram did not showed appearance of any degradation peaks in case of oxidative, thermal, and photo degradation. Typical chromatograms obtained for RM

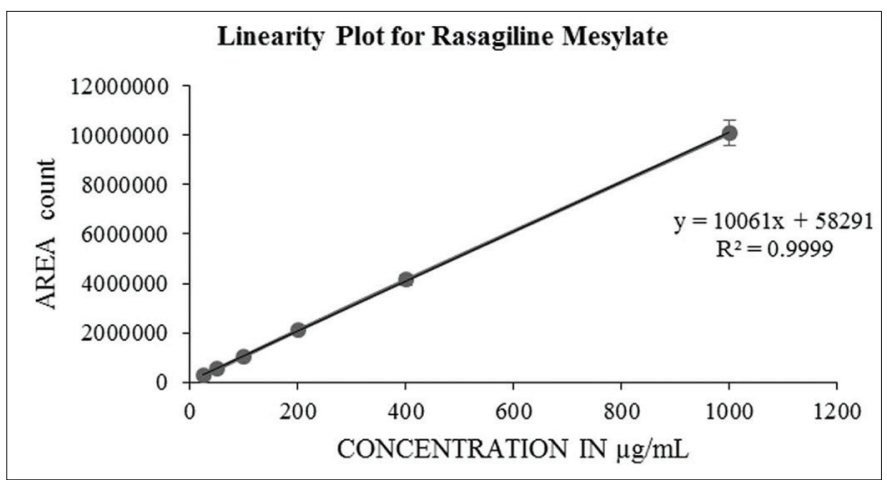

Figure 3. Calibration curve for RM.

Table 2. Results of RM method validation.

\begin{tabular}{|c|c|c|c|c|c|c|c|c|c|c|c|c|c|}
\hline \multicolumn{14}{|c|}{ Rasagiline mesylate concentration values found by method for various parameters $(\%)$} \\
\hline \multirow{3}{*}{ Sl. No. } & \multirow{3}{*}{ System } & \multirow{3}{*}{ Method } & \multicolumn{3}{|c|}{ Precision } & \multirow{2}{*}{\multicolumn{3}{|c|}{ Interday }} & \multicolumn{4}{|c|}{ Robustness } & \multirow[t]{3}{*}{ Ruggedness } \\
\hline & & & \multicolumn{3}{|c|}{ Intraday } & & & & \multicolumn{2}{|c|}{ Change in flow rate } & \multicolumn{2}{|c|}{ Change in wavelength } & \\
\hline & & & Hour 1 & Hour 2 & Hour 3 & Day 1 & Day 2 & Day 3 & $0.6 \mathrm{ml}$ & $1 \mathrm{ml}$ & $263 \mathrm{~nm}$ & $273 \mathrm{~nm}$ & \\
\hline 1 & 104.359 & 105.070 & 100.194 & 99.949 & 100.064 & 100.194 & 100.138 & 100.040 & 100.105 & 100.037 & 100.120 & 99.990 & 99.684 \\
\hline 2 & 104.382 & 105.243 & 100.223 & 100.055 & 100.177 & 100.223 & 100.051 & 99.950 & 99.986 & 99.681 & 99.915 & 100.061 & 99.948 \\
\hline 3 & 104.244 & 105.200 & 100.097 & 99.908 & 99.907 & 100.097 & 99.889 & 99.990 & 99.895 & 100.281 & 99.964 & 99.949 & 99.578 \\
\hline 4 & 104.086 & 105.034 & 99.817 & 100.014 & 99.793 & 99.817 & 100.082 & 100.001 & 100.107 & 100.017 & 100.121 & 99.992 & 99.766 \\
\hline 5 & 104.003 & 104.874 & 99.927 & 100.009 & 100.116 & 99.927 & 100.159 & 100.057 & 99.859 & 99.816 & 99.951 & 100.060 & 99.261 \\
\hline 6 & 103.907 & 104.805 & 99.742 & 100.064 & 99.944 & 99.742 & 99.681 & 99.962 & 99.958 & 100.291 & 99.649 & 99.499 & 99.592 \\
\hline Std dev & 0.19501 & 0.17325 & 0.20095 & 0.06068 & 0.14371 & 0.20095 & 0.18314 & 0.04226 & 0.10835 & 0.26975 & 0.09565 & 0.05069 & 0.22907 \\
\hline Average & 104.215 & 105.038 & 99.998 & 99.987 & 100.001 & 99.998 & 100.002 & 99.998 & 99.965 & 99.993 & 100.001 & 100.001 & 99.638 \\
\hline \%RSD & 0.18713 & 0.16494 & 0.20095 & 0.06068 & 0.14371 & 0.20095 & 0.18314 & 0.04226 & 0.10839 & 0.26975 & 0.09565 & 0.05069 & 0.22990 \\
\hline
\end{tabular}


Table 3. Results of RM forced degradation studies.

\begin{tabular}{ccccc}
\hline Sl. No. & Nature of stress & Retention time (minute) \pm SD* & Area \pm SD* & $\begin{array}{c}\text { Retention times }(\text { min) for } \\
\text { degradation products }\end{array}$ \\
\hline 1 & Acid hydrolysis & $2.58 \pm 0.199$ & $560921 \pm 0.292$ & 47.39 \\
2 & Base hydrolysis & $2.71 \pm 0.608$ & $122679 \pm 0.910$ & 88.49 \\
3 & Oxidation at $80{ }^{\circ} \mathrm{C}$ & $2.64 \pm 0.448$ & $953673 \pm 0.623$ & 31.32 \\
4 & Thermal degradation at $80^{\circ} \mathrm{C}$ & $2.64 \pm 0.062$ & $1056733 \pm 0.128$ & 0.903 \\
5 & Photo degradation UV $254 \mathrm{~nm}$ & $2.63 \pm 0.083$ & $1057526 \pm 0.076$ & -3.81 \\
\hline
\end{tabular}
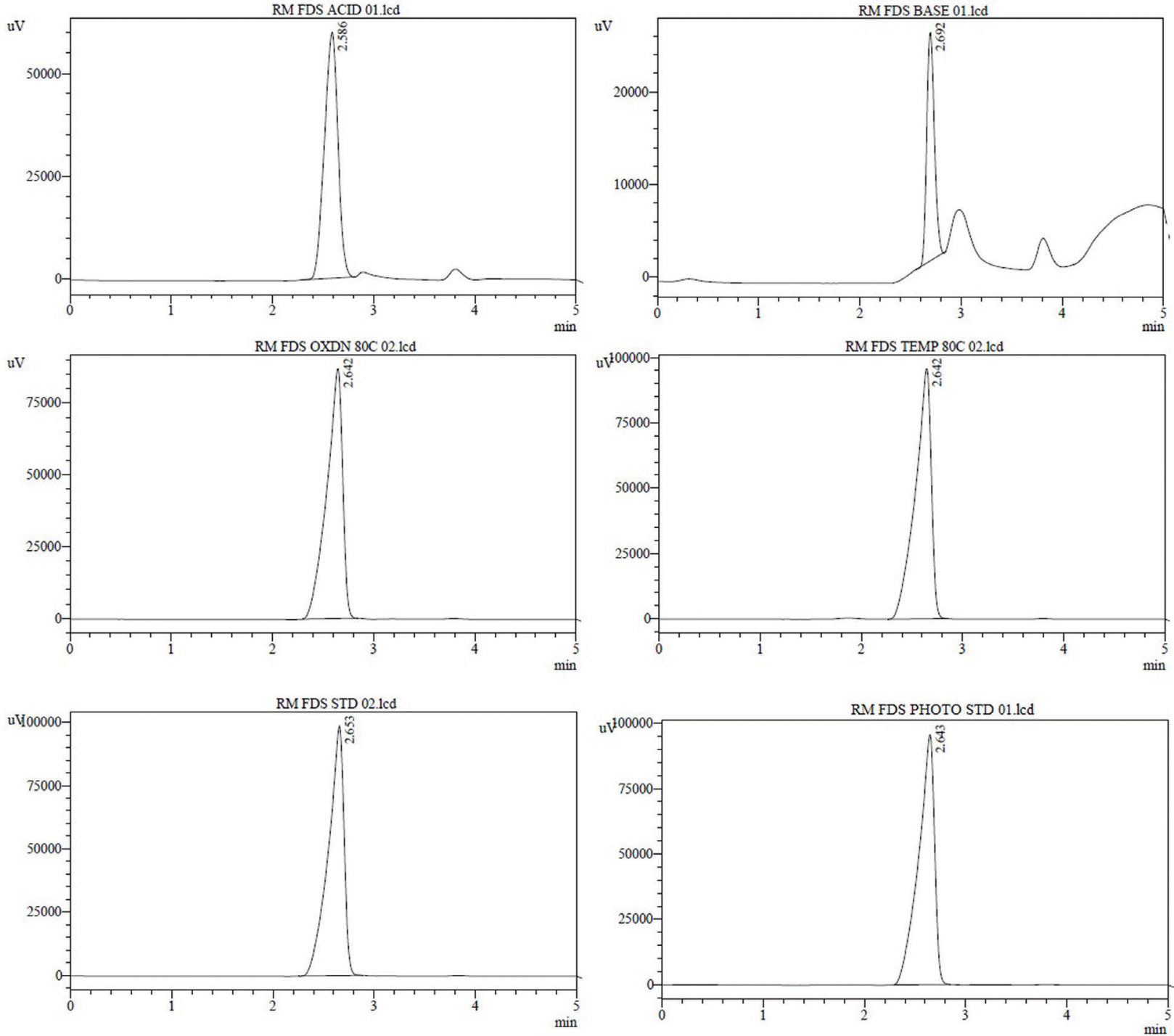

Figure 4. Forced degradation study of RM; HPLC chromatographs for different stressed conditions.

under different conditions are shown in Figure 4. From the forced degradation study, it can be stated that RM peak obtained in all the stress conditions was homogenous and the presence of its degradation products did not affect the principal analyte peak. This confirms the stability indicating nature of the developed method. This proves the method is able to determine $\mathrm{RM}$ in presence of its degradation products.

\section{Estimation of RM in tablet dosage forms}

Estimation of RM in marketed product, Rasalect 1 tablets, was carried out employing the developed method. Satisfactory results were obtained with the label claim. The percentage assay of RM in marketed formulation was found to be $99.03 \%$. The results showed that there was no interference of excipients and no impurities were observed in samples for the developed method (Table 4). 
Table 4. Estimation of RM in marketed product (Rasalect-1).

\begin{tabular}{|c|c|c|c|c|c|c|c|}
\hline Brand name & $\begin{array}{c}\text { Standard peak } \\
\text { area }\end{array}$ & Average & $\begin{array}{l}\text { Sample peak } \\
\text { area }\end{array}$ & Average & $\begin{array}{l}\text { Amount found } / \text { tablet } \\
(\mathrm{mg}) \pm \% \mathrm{SD}\end{array}$ & $\begin{array}{l}\text { Label claim } \\
\qquad(\mathrm{mg})\end{array}$ & $\begin{array}{l}\% \text { amount } \\
\text { found }\end{array}$ \\
\hline \multirow{6}{*}{ Rasalect 1} & $1,068,701$ & \multirow{6}{*}{1067224} & $1,642,579$ & \multirow{6}{*}{$1,643,306$} & \multirow{6}{*}{$0.99025 \pm 0.18$} & \multirow{6}{*}{1} & \multirow{6}{*}{99.025} \\
\hline & $1,067,763$ & & $1,640,618$ & & & & \\
\hline & $1,066,044$ & & $1,646,167$ & & & & \\
\hline & $1,068,103$ & & $1,643,642$ & & & & \\
\hline & $1,068,916$ & & $1,634,842$ & & & & \\
\hline & $1,063,818$ & & $1,651,986$ & & & & \\
\hline
\end{tabular}

\section{CONCLUSION}

The analytical methods developed earlier for quantification of RM by various researchers had higher retention times like 4.152 and 5.5 minutes. Further method for the simultaneous estimation of process related impurities and degradation products of RM had retention time of 33.1 minutes. Enhanced retention time attributes to higher mobile phase consumption and less turnout of the samples making the analytical methods less economical. The present RP-HPLC method for the determination of RM in API and pharmaceutical dosage form is simple, rapid, economical, accurate, and precise. Satisfactory results were observed for all the tested validation parameters for the developed method. The retention time was found to be 2.6 minutes due to this the method require less time, the consumption of the mobile phase is less. The preparation of mobile phase involved no weighing procedures there by reduces the human and instrumental error and increase the efficacy of the method when compared to other methods available in the literature. The stress testing results revealed that the method is specific. Hence, the developed method could be conveniently used for quantification of RM in API and in pharmaceutical dosage forms.

\section{ACKNOWLEDGMENT}

The authors would like to thank the M/s Apotex Pvt. Limited, Bangalore, Karnataka, India for providing gift samples of working standard and bulk drug (API) of rasagiline mesylate with certificate of analysis.

\section{FUNDING}

\section{None}

\section{CONFLICT OF INTEREST}

Authors declare that there are no conflict of interest.

\section{REFERENCES}

Alarfaj NA. Stability-indicating liquid chromatography for determination of clopidogrel bisulfate in tablets: Application to content uniformity testing. J Saudi Chem Soc, 2012; 16:23-30.

Blessy M, Patel RD, Prajapati PN, Agrawal YK. Development of forced degradation and stability indicating studies of drugs - a review. J Pharm Anal, 2014; 4:159-65.

Chandran S, Singh RSP. Comparison of various international guidelines for analytical method validation. Pharmazie, 2007; 62:4-14.

Dey S, Subhasis Patro S, Suresh Babu N, Murthy PN, Panda SK, Development and validation of a stability-indicating RP-HPLC method for estimation of atazanavir sulphate in bulk. J Pharm Analysis, 2017; 7:134-40.
ICH Guideline Q1A(R2). Stability testing of new drug substances and products. ICH, Switzerland, 2003. Available via https://www.ich.org/ fileadmin/Public_Web_Site/ICH_Products /Guidelines/Quality/Q1A_R2/ Step4/Q1A_R2_Guideline.pdf (online).

ICH Guideline Q2 (R1). Validation of analytical procedures: text and methodology. ICH, Switzerland, 2005. Available via http://www. ich.org/fileadmin/Public_Web_Site/ICH_Products /Guidelines/Quality/ Q2_R1/Step4/Q2_R1_Guideline.pdf (online).

Kongkiatpaiboon S, Duangdee N, Chewchinda S, Poachanukoon $\mathrm{O}$, Amnuaypattanapon K. Development and validation of stability indicating HPLC method for determination of adrenaline tartrate. J King Saud Univ Sci, 2017; 31(1):48-51.

Patel PR, Mulgund SV. Development and validation of a spectrophotometric method for estimation of rasagiline mesylate in bulk and tablet dosage form. Int J Drug Dev Res, 2013; 5:174-7.

Ravi PR, Aditya N, Cherian L, Patil S. LC method for determination of rasagiline mesylate in different plasma matrices and its application to oral pharmacokinetic study in rabbits. J Chrom Sci, 2013; $51: 1-7$.

Singaram K, Suggala VS, Garikapati D. Development and validation of a stability-indicating HPTLC method for analysis of rasagiline mesylate in the bulk drug and tablet dosage form. Chrom Res Int, 2012:1-6.

Sundaramurthy P, Varadarajan B, Rajasekhar R, Raju I. Validated and stability indicating dissolution test with reverse phase- HPLC analysis for Rasagiline Mesyalte in tablet dosage form. Int J Pharm Rev Res, 2011; 10(2):18-23.

Sunil Reddy P, Sudhakar Babu K, Navneet Kumar. Development and validation of a stability-indicating RP-HPLC method for the simultaneous estimation of process related impurities and degradation products of rasagiline mesylate in pharmaceutical formulation. J Chrom Sci, 2013; 51:242-9.

Vamsi KM, Rajendra ND, Jalachandra R,Venugopal P, Sandeep P, Madhavi G. Quality by design (QbD) approach to develop HPLC method for eberconazole nitrate: application to hydrolytic, thermal, oxidative and photolytic degradation kinetics. J Saudi Chem Soc, 2016; 20:S313-22.

How to cite this article:

Bhatta RG, Satheesha Babu BK, Sadashivaiah R. Quantification of rasagiline mesylate by stability indicating RP-HPLC method: Development and validation. J Appl Pharm Sci, 2019; 9(09):059-065. 